\title{
Management of orbital fractures: challenges and solutions
}

\author{
This article was published in the following Dove Press journal: \\ Clinical Ophthalmology \\ 17 November 2015 \\ Number of times this article has been viewed
}

\author{
Jennings R Boyette' \\ John D Pemberton² \\ Juliana Bonilla-Velez' \\ 'Department of Otolaryngology- \\ Head and Neck Surgery, ${ }^{2}$ Department \\ of Ophthalmology, University of \\ Arkansas for Medical Sciences, Little \\ Rock, AR, USA
}

\begin{abstract}
Many specialists encounter and treat orbital fractures. The management of these fractures is often challenging due to the impact that they can have on vision. Acute treatment involves a thorough clinical examination and management of concomitant ocular injuries. The clinical and radiographic findings for each individual patient must then be analyzed for the need for surgical intervention. Deformity and vision impairment can occur from these injuries, and while surgery is intended to prevent these problems, it can also create them. Therefore, surgical approach and implant selection should be carefully considered. Accurate anatomic reconstruction requires complete assessment of fracture margins and proper implant contouring and positioning. The implementation of new technologies for implant shaping and intraoperative assessment of reconstruction will hopefully lead to improved patient outcomes.
\end{abstract}

Keywords: orbital fracture, orbital blowout, orbital floor

\section{Introduction}

Fractures of the orbit are common and challenging to manage. They deserve special consideration because surgical or observational management may result in compromise to vision and/or globe position. Most orbital fractures occur in males in their second decade of life. ${ }^{1,2}$ In adults, motor vehicle accidents and assault are the most common mechanisms of injury. ${ }^{1-4}$ However, in pediatric patients falls and sportsrelated injuries are more common. ${ }^{5}$ Orbital fractures are often broadly referred to as "blowout" fractures; however, not all orbital fractures are isolated orbital injuries. Orbital fractures may be isolated, or combined, with other nonorbital injuries (head, neck, and spine). Many maxillofacial injures involve the orbit, eg: 1) Le Fort II and III fractures, 2) zygomaticomaxillary complex (ZMC) fractures, and 3) nasoorbitoethmoid fractures.

Most surgeons describe the orbital fracture according to the location within the orbit (floor, medial wall, lateral wall, and roof). However, this simplifies the often complex nature of these fractures. Several classification schemes have been proposed to define isolated, multiwalled, and comminuted orbital fractures, as well as, soft tissue displacement. ${ }^{6-9}$ Essentially, having a classification scheme will improve intersurgeon communication, provide guidelines for surgical management (indications and timing), and establish a standard for research.

Conceptually, management of these injuries has changed little over the years. However, advances in maxillofacial/orbital imaging, introduction of intraoperative navigation systems, better evidence-based surgical indications and timing, and improved implant designs have led to a reappraisal of time-honored techniques and guidance. Although treatment considerations for orbital roof and medial wall fractures
Correspondence: Jennings R Boyette Department of Otolaryngology-Head and Neck Surgery, University of Arkansas for Medical Sciences, 430I West Markham, Slot 543, Little Rock, AR 72205, USA

$\mathrm{Tel}+\mathrm{I} 50 \mid 6865140$

$\mathrm{Fax}+\mathrm{I} 5016868029$

Email jrboyette@uams.edu 
will be discussed, this review will primarily focus on challenges and solutions for orbital floor fractures.

\section{Pathophysiology}

Many hypotheses have been proposed regarding the pathogenesis of the "blowout" fracture. One of the oldest is the boneconduction theory, which suggests that a force, not powerful enough to fracture the rim, will propagate along the bone to fracture the weaker orbital floor (Le Fort). Pfeiffer proposed the "Globe-to-Wall Theory", which is when a force pushes the globe into the orbit and causes the globe to contact the orbital floor, resulting in a floor fracture. ${ }^{10} \mathrm{~A}$ similar and more popular theory is the "hydraulic mechanism", whereby the fracture is the result of increased intra-orbital pressure from the eye entering the orbit and not due to direct contact. ${ }^{11,12}$ The cause is likely a conglomeration or some iteration of all three.

\section{Clinical evaluation}

In patients with orbital fractures, associated ocular injuries are present in up to $29 \%$ of the patients. ${ }^{13}$ It is imperative that an eye exam is done promptly to mitigate the risk of vision loss or vision compromise. Blindness associated with orbital fractures has been reported at $0.7 \%-10 \% .{ }^{14-17}$ The complete eye exam is divided into eight parts: vision, eye pressure, ocular motility, pupil exam, visual field, slit lamp ocular exam, retinal exam, and external exam. Some of these exam elements (vision, motility, and visual field) require a cooperative and conscious patient. Fortunately, many of the elements are not imperative in dealing with the emergent acute stages of an orbital injury. When possible, the complete eye exam should be done.

Typically, an orbital fracture presents with periocular swelling, proptosis (acute stage), enophthalmos (later stage and large fracture), ecchymosis, chemosis, V2 hypesthesia, and subconjunctival hemorrhage. When faced with these physical findings, one must perform an external exam of the periocular tissue and determine globe integrity before proceeding with ocular function testing. Any obvious globe rupture or concern of one should initiate gross vision assessment (if conscious), vaulted eye protection, orbital imaging, and an immediate ophthalmology consult. If an eye surgeon is not available, the patient should be referred elsewhere urgently. Some signs of possible globe rupture are $360^{\circ}$ of subconjunctival hemorrhage, misshapen pupil (peaked, corectopia), and flat anterior chamber.

If the globe is intact, the next most important exam element is the eye pressure. Elevated eye pressure from an orbital compartment syndrome (orbital swelling and retrobulbar hemorrhage) can lead to optic neuropathy and blindness. Traumatic optic neuropathy is reported to occur in $3 \%$ of the isolated orbital fractures. ${ }^{18}$ If the eye pressure is elevated, an immediate canthotomy and cantholysis should be performed. Pressures below $40 \mathrm{mmHg}$ can be treated with eye pressure lowering drops. However, if conservative therapy fails, a canthotomy and cantholysis needs to be considered.

A slit-lamp examination can be performed to further evaluate the cornea and retina. This can detect associated injuries such as corneal abrasions, lens dislocations, hyphema, commotio retinae, and retinal detachments. Commotio retinae is one of the most common associated ocular injuries in patients with fractures $(22 \%)$, followed by hyphema and corneal injuries. ${ }^{13}$

Assessment of extraocular movement is even more important in children due to the so-called white eye syndrome, in which the eye looks otherwise completely normal except for extraocular movement limitation. Since greenstick fractures are more common in children, these fractures causing a trapdoor effect and muscle impingement are more likely to be seen in the pediatric population (Figure 1). These patients may also have pain with eye movement, nausea, vomiting, and bradycardia that can mimic the symptoms of a closed head injury.

In general, it is prudent to obtain orbital imaging in all patients who suffer orbital trauma. Holmgren et al found that $12 \%$ of the trauma patients who had a head computed tomography $(\mathrm{CT})$ also had a maxillofacial fracture. ${ }^{19}$ Additionally, he found that upon review of axial CT images of head, orbital fractures were commonly identified. ${ }^{19}$

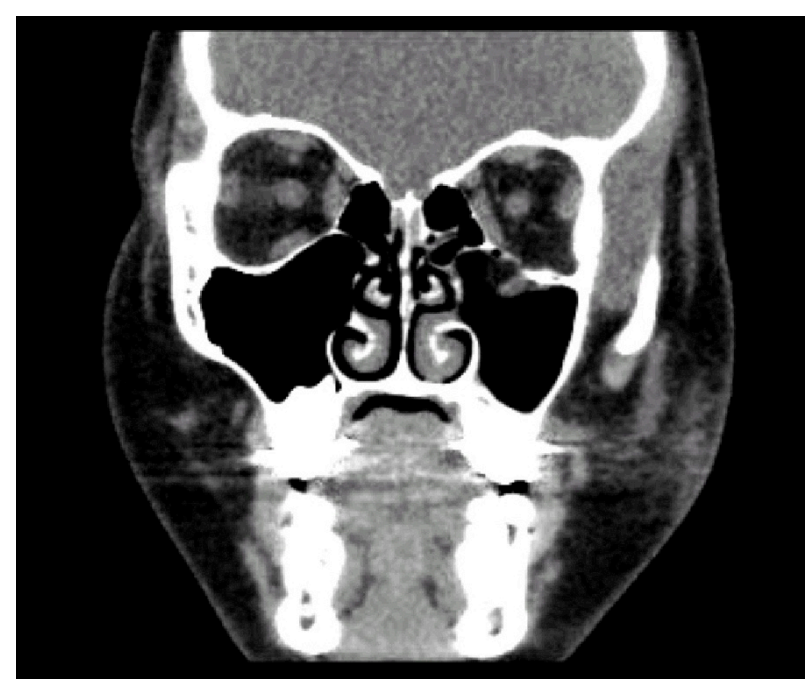

Figure I Coronal CT imaging of a pediatric patient with a left orbital floor greenstick fracture.

Note: The entrapped inferior rectus located within the maxillary sinus. Abbreviation: CT, computed tomography. 


\section{Imaging}

CT imaging remains the gold standard for detecting and defining orbital fractures. Imaging of the entire face is recommended as concomitant fractures are commonly encountered. Coronal and sagittal reconstructions (from axial slice thickness $<2 \mathrm{~mm}$ ), and three-dimensional (3D) rendering is recommended to optimize maxillofacial assessment (Figure 2). The medial wall is best visualized in a bone window axial view. The sagittal view allows for assessment of the orbital floor and availability of the posterior ledge for implant support. Both coronal and sagittal views can be used to assess the orbital soft tissue and evaluate for fat herniation or ocular muscle entrapment.

\section{Clinical management}

Following the diagnosis of an orbital blowout fracture (and the ocular examination), the initial management is to prevent further injury to the globe while determining if surgical intervention is indicated. It is important to educate the patient to avoid blowing their nose, as air from the sinonasal tract can be forced into the orbit. This can result in an orbital compartment syndrome that can cause blindness. Periorbital edema can be lessened with cold compresses and by keeping the head of bed elevated. Ensure that the eyelids can close in order to protect the ocular surface, more specifically the cornea, from exposure - ophthalmic ointment or a temporary tarsorraphy may be needed.

\section{Antibiotics}

There are many studies detailing the use of antibiotics in maxillofacial fractures, but very few that specifically assess the use of antibiotics in isolated orbit fractures. ${ }^{20-22}$ After a thorough review of the published studies, Mundinger et al found no convincing evidence to support preoperative or postoperative antibiotic use in upper or midface fractures. ${ }^{23}$ However, intraoperative administration of antibiotics is well supported. ${ }^{23-25}$ Patients with preexisting sinus disease may be at an increased risk for developing orbital cellulitis, as this correlation has been reported in small series. ${ }^{26}$ Prospective studies examining prophylactic antibiotic use are needed. At present, the authors only use antibiotics intraoperatively.

\section{Indications for surgery}

Many orbital fractures do not lead to enophthalmos, diplopia, or ocular motility dysfunction. ${ }^{27,28}$ However, predicting future outcome in the acute setting can be difficult. The decision to observe a fracture or proceed with surgery is based on the clinical exam findings, orbital imaging, and assessment of the risk and benefit of either option. Indications for surgical intervention can be separated into immediate versus delayed repair.

\section{Immediate repair}

The oculocardiac reflex may be elicited in an orbital fracture due to entrapment of the extraocular muscles. This can result in pronounced bradycardia, vomiting, syncope, and even asystole. ${ }^{29}$ Thus, urgent surgery is necessary to release the incarcerated tissues and relieve the stimulus. The oculocardiac reflex is more commonly encountered with trapdoortype fractures where a segment of bone is displaced, and then hinges back to a more normal position, entrapping the orbital tissues. This is more common in pediatric patients presumably due to more elastic orbital bone. ${ }^{30}$ It is also found to be more commonly associated with entrapment of the

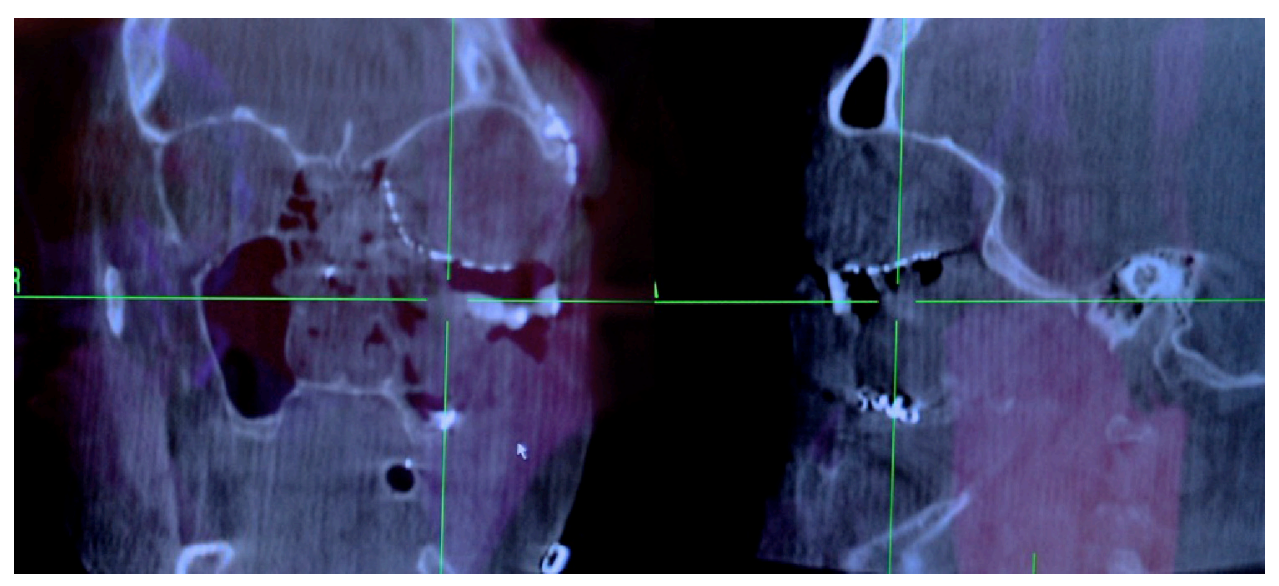

Figure 2 Example of an intraoperative CT scan used to evaluate placement of an orbital floor titanium implant.

Note: Coronal and sagittal reconstructions.

Abbreviation: $\mathrm{CT}$, computed tomography. 
inferior rectus muscle. ${ }^{30}$ Jordan et al referred to these type of injuries as "white-eyed" fractures, since the child may have a normal-appearing eye until gaze restriction is found on extraocular movement exam. ${ }^{31}$ Therefore, it is important to carefully study the CT scans of patients exhibiting these signs and symptoms, as the displaced extraocular muscle on the other side of the bone may be missed on a cursory review of the images.

Studies have shown that early intervention in cases of muscle entrapment resulted in less postoperative diplopia. ${ }^{31-37}$ It is suggested that the muscle may undergo ischemic injury or become dysfunctional from fibrosis or neuropathic injury. ${ }^{38}$ It can be difficult to assess true muscle entrapment in the acute phase as most patients will have some degree of movement restriction as a result of orbital swelling. ${ }^{39}$ Forced duction testing can help clarify if entrapment exists. Another relative indication for immediate intervention is significant enophthalmos at the time of injury. Very large bony defects can displace the globe into the maxillary sinus. Certainly, these cases warrant surgical repair to prevent long-term enophthalmos, but some surgeons recommend early intervention for this type of significant displacement. ${ }^{33,34}$

\section{Delayed repair (within 2 weeks)}

The majority of orbital fractures are managed initially with observation, then surgical intervention, if indicated, within 14 days of injury. The delay allows periorbital edema to decrease, which can assist in subsequent examinations and provides a window for concomitant injuries to be addressed. Diplopia is common in orbital fractures, but most improve within the first 2 weeks following the injury. Indications for surgery are enophthalmos $(>2 \mathrm{~mm})$, ocular motility dysfunction, and persistent diplopia in primary gaze or reading position, CT findings of ocular muscle impingement and over $50 \%$ of floor involvement, progressive V2 hypesthesia, and abnormal forced duction testing. . $3,34,38,40$ On initial presentation, these exam findings may be difficult to obtain due to edema, patient cooperation, and equipment limitations. The decision to proceed with surgery should rely on the collection of indications found in both the clinical and radiographic assessments.

Enophthalmos becomes clinically noticeable between eyes at 3 and $4 \mathrm{~mm} .{ }^{41}$ A $5 \%$ increase in orbital volume $\left(1 \mathrm{~cm}^{3}\right)$ may be enough to cause this finding. ${ }^{38,42,43}$ If enophthalmos is not present clinically, the CT scan is used to subjectively predict volume change based on fracture displacement and fracture size. In general, this has been defined as displacing more than $1 \mathrm{~cm}^{2}$ or greater than $50 \%$ of the orbital floor. ${ }^{33,34,38,44}$ Fracture location is important as well. Burm and
Oh found $40 \%$ of medial wall fractures result in enophthalmos. ${ }^{45}$ Furthermore, fractures at the junction of the medial wall and orbital floor are particularly prone to development of enophthalmos and chronic diplopia. ${ }^{39,45,46}$

The degree of bony disruption may not be the only predictor of developing enophthalmos or persistent diplopia. Harris et al examined the amount of soft tissue herniation in proportion to the size of the bony defect and found that when the amount of soft tissue displaced was greater than the size of the defect, surgery lead to better results. ${ }^{9}$ Furthermore, disruption of the periorbital can be seen to result in changes in the inferior rectus on $\mathrm{CT}$. Rounding of the inferior rectus on coronal CT is predictive of postoperative enophthalmos. ${ }^{47}$ Thus, when the inferior rectus takes on a more vertical orientation - when the height-to-width ratio is greater than or equal to $1-$ it is predictive of late enophthalmos. ${ }^{47}$

\section{Timing of repair}

Deferring surgery until periorbital edema decreases affords greater exposure and mitigates risk of compartment syndrome. However, delay increases the risk that impinged orbital tissues will develop fibrosis and cause chronic diplopia. In the absence of indications for immediate repair, a 2-week window for repair has been supported in the literature. ${ }^{33,34,38,44,48,49}$ If there is a question of entrapment based upon CT or forced duction testing, operative intervention within 48 hours, or as soon as possible, should be considered. ${ }^{38}$

\section{Surgical management Approach}

The approach to the fracture site depends upon the type of injury, surgeon experience, and available equipment. Subciliary, subtarsal, and transconjunctival incisions are the most commonly utilized. The subciliary approach has been associated with a much higher complication rate, with ectropion resulting in approximately $12.9 \%$ of cases. ${ }^{50}$ The subtarsal approach is associated with less ectropion and if placed appropriately should not result in a conspicuous scar $(1 \%-3 \%) .{ }^{51-53}$ Most surgeons prefer the transconjunctival approach to the orbital floor because there is no visible scar and the complication rate is very low - less than $1 \%$ in many series. ${ }^{54-56}$ Medial wall fractures are difficult to repair, though there are many approaches. Some of the most common approaches are the transcutaneous (Lynch incision), transconjunctival inferior fornix, transcaruncular, and endoscopic trans-ethmoidal. The transcaruncular approach is very popular because it easily combines with the transconjunctival approach. 


\section{Endoscopic approach}

Interest in the endoscopic approach to the floor and medial wall has increased as surgeons try to avoid eyelid complications and improve visualization of the orbital walls. Cheung et al recently reviewed nine studies involving 172 patients in which endoscopic approaches were used for orbital wall fractures. ${ }^{57}$ No patients underwent conversion to an open approach and the most common complication was transient cheek numbness. ${ }^{57}$

To gain access to the orbital floor, a sublabial approach is utilized to open a window of bone in the anterior wall of the maxillary sinus just below the infraorbital nerve. Angled endoscopes are used to visualize the floor defect and the herniated orbital contents. Once the orbital contents are reduced, stable circumferential bony shelves in the floor should be identified, and a flexible implant (such as $0.85 \mathrm{~mm}$ porous polyethylene) can be used to occlude the defect. Ducic and Verret reported using the anterior maxillary sinus wall bone as an autograft. ${ }^{58}$

Medial wall defects require an anterior ethmoidectomy, which requires some experience with endoscopic sinus surgery. The use of powered microdebriders is discouraged for these procedures in order to avoid inadvertent injury to the orbital contents. Image guidance is particularly useful in these cases. Again, thin flexible implants are commonly used for reduction.

Endoscopic approaches can be technically challenging. Even if an eyelid incision is utilized for repair, the endoscope can provide a valuable assessment of soft tissue reduction and implant positioning. In orbital fractures combined with a ZMC or Le Fort fracture where a bony defect in the maxillary sinus already exists, using the endoscope to visualize the orbital floor implant can provide confirmation of proper placement (Figure 3).

\section{Surgical technique}

Concomitant orbital and maxillofacial fractures are repaired in a particular sequence. The first step is to obtain a baseline ocular motility by a forced duction test. The orbital rim is exposed by one of the approaches mentioned earlier. Repair of an orbital floor defect proceeds in a similar manner regardless of approach. Once the orbital rim is reached, dissection continues in the subperiosteal plane into the orbit and then along the orbital floor in a $20^{\circ}$ cephalic direction. Deeper in the orbit a malleable retractor is used to elevate the orbital tissues and improve visibility to identify the orbital fracture defect. Orbital tissue is frequently herniating into the fracture. This tissue should be delicately approached from

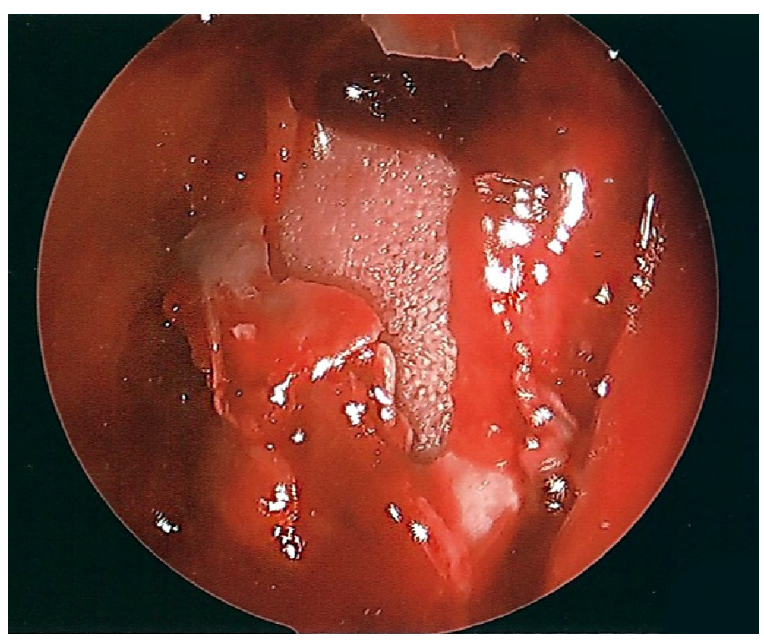

Figure 3 Endoscopic view of the orbital floor from the maxillary sinus. Notes: A porous polyethylene implant placed via an eyelid approach is assessed to ensure no herniated orbital contents are remaining in the sinus and that the implant is resting on bony ledges.

side-to-side, avoiding inadvertent penetration of the tissue with the freer/elevator. Penetration into the tissue can expose difficult to retract orbital fat, making visibility more cumbersome. Segments of bone limiting elevation of soft tissue can be removed to improve mobility of the orbital tissue back into the orbit. Once the infraorbital nerve is identified, the tissues above and medial to the nerve can be mobilized into the orbit and separated from orbital floor bone fracture segments and the maxillary sinus mucosa. Dissection is continued until the entire orbital fracture ring can be identified and the bone ledges deemed stable to support an implant (especially important is the posterior ledge). The implant is then sized and shaped to cover the fracture ring. The size of the implant should not be significantly larger than the defect as this can affect ocular motility and globe position.

In severe fractures, the posterior floor can be unstable or unidentifiable, which makes implant positioning difficult and increases the risk of postoperative ophthalmic functional deficits. In these cases, it is recommended to use more rigid implants that can be fixated to the infraorbital rim and cantilevered toward the posterior orbital fracture ledge. If the implant is projecting too high, it can cause hyperglobus and ocular motility problems. Additionally, if the implant is positioned too deeply into the orbit, it can impinge the optic nerve at the apex and cause vision loss.

\section{Assessing reduction and implant placement}

While not a widespread practice, many surgeons advocate for the use of early postoperative CT imaging to assess implant 
position. This allows the surgeon to address implant issues earlier, but requires another trip back to the operative suite. Ideally, intraoperative assessment would help solve this issue.

Many facilities have image guidance systems as their use has become widespread in endoscopic sinus surgery. Preoperative planning using mirror-image overlay of the patient's normal orbit provides an on-screen guide for placement and contour of the implant. The software to perform mirror-image overlay is not available on all systems. However, even simple image guidance systems can provide important information such as verifying location of a posterior ledge or comparing the slope of proposed implant placement to the contralateral side. In 113 consecutive cases of complex orbital fractures, Bly et al found the use of image guidance to significantly decrease the incidence of postoperative diplopia and to significantly reduce to need for revision surgery in fractures that involved multiple orbital walls. ${ }^{59}$

Intraoperative imaging has the advantage of showing the actual implant as it is positioned in the orbit, if a radioopaque implant, such as titanium, is used. Mobile CT scanners have become much less cumbersome in recent years and setup and scan times have been reduced to only a few minutes. With these cone-beam units, coronal, sagittal, and even $3 \mathrm{D}$ views can be created without a significant increase in radiation exposure. While very thin bone fragments are sometimes difficult to visualize, implant positioning is very clear. In a recent study, Shaye et al found intraoperative CT use to average approximately 14.5 minutes per case, and to have prompted intraoperative revisions in $24 \%$ of maxillofacial fracture cases. ${ }^{60}$

\section{Postoperative care}

Prior to discharge from the recovery room, basic visual acuity should be assessed. While the patient should expect to have pain and periorbital edema, instructions should be given regarding symptoms of retrobulbar hemorrhage such as worsening pain, sudden swelling, or vision loss. Elevating the head of bed will decrease postoperative edema. Cold packs may provide some comfort early after surgery. Topical ophthalmic ointments are helpful to moisturize the cornea, especially if edema affects eyelid closure. No nose blowing and avoidance of heaving lifting is recommended for at least 2 weeks following surgery.

\section{Selection of implant material}

Reconstruction of the orbit can be achieved using a wide variety of implants (Table 1). As with any other type of implant, materials for orbital reconstruction will vary in the specific properties they possess and it will be the surgeon's assessment of the patient's fracture, age, location, etc, that will determine the material selection. Historically, autografts were the preferred method for orbital reconstruction, while alloplasts have gained popularity with improvement in material engineering and biocompatibility, and now constitute the most widely used implants for orbital reconstruction.

\section{Autogenous materials}

\section{Autogenous bone}

Although bone has good strength, no sharp edges, can be fixed to adjacent bone and is radiopaque, it can have a variable degree of resorption that can be problematic, and its lack of pliability creates a significant difficulty for adequate molding into complex shapes. ${ }^{61}$ The calvarium, iliac crest, nasal, maxillary, and mandibular bone have been used as donor sites, with the first two being the most commonly used. ${ }^{62}$

Due to the close proximity to the operating field that facilitates harvest and the intrinsic shape of the bone, split calvarial grafts are commonly used. Data accrued in the past 10 years have shown that the repair of orbital fractures with calvarium is safe and has an acceptable reduction of enophthalmos and diplopia, but results in less accurate reconstruction of the intrinsic shape of the orbit with less precise recovery of orbital volume. ${ }^{62-65}$ The authors do not recommend it being used as primary means for reconstruction because of the potential for donor site morbidity, but it could be considered in the setting of fractures in the growing skull.

Prospective outcomes for internal orbital reconstruction using a free iliac bone graft were reported by Kontio et al on 24 patients. The technique was considered reliable and with a low rate of enophthalmos and hypophthalmos. There was an $80 \%$ rate of bone resorption; therefore, slight overcorrection may be necessary. ${ }^{66}$

\section{Autologous cartilage}

Septal and auricular cartilage have been used for reconstruction of orbital defects, but although they are completely biocompatible, they provide limited structural support and are prone to resorption. Studies have shown that the harvest technique is simple, and there is minimal to no donor site morbidity, with septal cartilage having better results than conchal cartilage due to the inherent shape of the graft. ${ }^{62,67,68}$

\section{Alloplastic materials}

\section{Titanium mesh}

Titanium is highly biocompatible, easily adjusted to architecturally fit simple and complex orbital defects, provides strong support, does not alter its shape or location over time, and it can be easily fixed to adjacent bone. It has 
Table I Advantages and disadvantages of the most common implants used for orbital reconstruction

\begin{tabular}{|c|c|c|c|}
\hline Implant material & Advantages & Disadvantages & Indications \\
\hline \multicolumn{4}{|l|}{ Autograft } \\
\hline \multirow[t]{4}{*}{ Bone } & Most biocompatible & Donor site morbidity & Fractures in children $<7$ years of age \\
\hline & Good strength & Increases operative time and cost & \\
\hline & No sharp edges & Bone resorption & \\
\hline & Radio-opaque & Difficult to adjust shape & \\
\hline \multirow[t]{6}{*}{ Cartilage } & Most biocompatible & Minimal donor site morbidity & Small fractures \\
\hline & No sharp edges & Increases operative time and cost & \\
\hline & Prone to resorption & Poor structural support & \\
\hline & & Difficult to adjust shape & \\
\hline & & Not radio-opaque & \\
\hline & & Removes option for future nasal surgery & \\
\hline \multicolumn{4}{|l|}{ Alloplast } \\
\hline \multirow[t]{5}{*}{ Titanium mesh } & Biocompatible & Sharp edges and gaps allow tissue & Large orbital floor defects \\
\hline & Good strength for large defects & ingrowth making removal difficult & \\
\hline & $\begin{array}{l}\text { Malleable to be countoured to the } \\
\text { defect }\end{array}$ & Cost & \\
\hline & Radio-opaque & Isolated reports of infection & \\
\hline & Can prefabricate PSI & & \\
\hline \multirow[t]{4}{*}{ Porous polyethylene } & Biocompatible & Cost & Defects with good edges to support \\
\hline & Good strength for large defects & $\begin{array}{l}\text { Does not allow egress of fluid from } \\
\text { the orbit }\end{array}$ & implant \\
\hline & Can prefabricate PSI & & \\
\hline & Can be countoured to the defect & & \\
\hline \multirow[t]{3}{*}{ Resorbable sheeting } & Biocompatible & Cost & Can be used in small gaps $<2.5 \mathrm{~cm}^{2}$ \\
\hline & $\begin{array}{l}\text { Pliable and can be contoured to the } \\
\text { defect }\end{array}$ & $\begin{array}{l}\text { Concern for long-term stability } \\
\text { and support }\end{array}$ & $\begin{array}{l}\text { with stable medial and lateral } \\
\text { borders }\end{array}$ \\
\hline & Resorbable & Not radio-opaque & Fractures in children \\
\hline Patient-specific & Biocompatible & Requires an intact contralateral orbit & Extensive complex orbital defects \\
\hline \multirow[t]{8}{*}{ implant } & Digitally designed by the surgeon & Time required to obtain the implant & \\
\hline & based on the contralateral orbit & & \\
\hline & More stable than manually bent & Greater stiffness allows less & \\
\hline & titanium & intraoperative corrections & \\
\hline & Radio-opaque & & \\
\hline & Intraoperative navigation with $\mathrm{CT}$ & Requires surgeon familiarity & \\
\hline & guidance & with software & \\
\hline & & Cost & \\
\hline
\end{tabular}

Abbreviations: CT, computed tomography; PSI, patient-specific implant.

well-recognized osseointegration, is easily sterilized, and readily available, although at high cost. Unfortunately, the holes in the plates allow tissue ingrowth that may make removal more difficult, and the cut edges are prone to snaring periorbital soft tissue during placement. ${ }^{61,64}$ Studies have reported good outcomes and there has been one report of a surgical site infection requiring implant removal. ${ }^{62,64,65,69}$

\section{Porous polyethylene}

This implant material exhibits high biocompatibility, is easily trimmed into any desired shape, can be screw-fixated to bone, and has good strength with good long-term stability. The implant can usually be easily removed if needed, but on occasions, it can break into pieces, making removal more challenging. It has a low-infection rate, and these usually resolve with IV antibiotics with rare need for implant removal. ${ }^{61,62,70}$ The material is readily available, although at a high cost. There is no donor site morbidity or costs associated with increased operative time for implant harvest. ${ }^{61,62,70}$ However, it is not radiopaque.

There are titanium-reinforced porous polyethylene sheets, which combine the favorable properties of both implants. The titanium allows for easier fixation into bone and precise manipulation of the implant to fit complex orbital defects, and it makes the implant radiologically visible. ${ }^{61}$

\section{Resorbable sheeting}

Sheets made of poly-L/D-lactide, polyglactin, and polydioxanone have been commercially made from resorbable materials for orbital reconstruction. These are pliable and can be contoured to the orbital defect and have very low infection rate. 
Some authors suggest that if the implant is placed under periosteum, the surrounding tissues will create a fibrous scar preventing prolapse of tissues into the maxillary sinus after resorption, while others raise concerns for loss of long-term structural support and recommend its use for defects $<2.5$ $\mathrm{cm}^{2} \cdot{ }^{61,62,70,71}$ Further studies looking at long-term outcomes are needed to assess the long-term stability of the reconstruction.

\section{Patient-specific implants}

Using preoperative CT data, a construct can be specifically designed to mirror the non-affected orbit, thus creating a patient-specific implant (PSI). Titanium, polyetheretherketone, and glass-bioceramic have been used to manufacture PSI. ${ }^{72-77}$ These anatomically ideal models are intended to reduce the need for intraoperative manipulation, thus reducing operative time with more accurate reconstruction. ${ }^{72,73}$ Initial studies are promising demonstrating accurate fitting on all implants, no persistent postoperative visual impairments and no patient-reported sensation of foreign body. ${ }^{72}$ Unfortunately, there are still some limitations with the software from loss of data of thin bone altering the shape of the implant, as well as the risk of incorporating impurities into the implant resulting in rejection. ${ }^{77}$

\section{Pediatric considerations}

Traumatic involvement of the frontal bone and superior orbital rim are more common in children, especially under age 5 , due to the increased cranial vault to facial skeleton ratio. ${ }^{78,79}$ The vast majority of these fractures are treated with observation only. ${ }^{80}$ One possible issue that can arise is the "growing skull fracture", which is when the fracture site enlarges as the child grows. This potentially leads to a meningocele that can herniate into the orbit causing diplopia, pulsatile proptosis, and hypoglobus. ${ }^{81,82}$ Therefore, long-term follow-up with repeat CT scans is recommended.

It is important to emphasize that orbital greenstick "trapdoor" fractures with extraocular muscle entrapment are more common in children. This fracture is commonly known as the "white eye" orbital fracture (Figure 1). Urgent ophthalmology evaluation and CT imaging are recommended in cases of suspected pediatric orbital injury. Indications for surgical repair in children are essentially the same as in adults. However, children heal quickly; and muscle entrapment may result in fibrosis and shortening of the muscle within a couple days. Earlier intervention is recommended in children with evidence of entrapment, ${ }^{32,38}$ while in the absence of entrapment or immediate enophthalmos, the majority pediatric orbital fractures can be managed conservatively without surgical intervention. Pure orbital fractures in children are less likely to result in late enophthalmos. Surgical repair is not without risk of future problems due to growth and development. ${ }^{82}$ When surgery is indicated, the use of rigid implants may lead to orbitomalar growth restriction and maxillary hypoplasia. Many surgeons advocate for the use of split calvarial bone grafts in children younger than 7 years of age. ${ }^{38,78,83}$ However, as an alternative, resorbable alloplasts can be used successfully. ${ }^{62,84}$

\section{Complications}

The most common postoperative complications are diplopia, enophthalmos, and ectropion. The incidence of the most worrisome complication, vision loss after surgery, has been reported as between $0 \%$ and $0.4 \%{ }^{2,85,86}$ Most of these cases are related to postoperative intraorbital hemorrhage. ${ }^{85,86}$

Transient diplopia after surgery is common and will typically improve or resolve in a few weeks. ${ }^{87}$ However, the reported incidence of persistent diplopia ranges from $8 \%$ to $42 \% .{ }^{46,86,88-90}$ This degree of occurrence strongly reinforces the need for intraoperative forced duction testing, as implant impingement can certainly be a cause for persistent diplopia. With good implant positioning, it is presumed that trauma to the muscle, fibrosis, or nerve paresis is the reason for diplopia. ${ }^{91}$ Hosal and Beatty found postoperative diplopia to be more likely in older patients and those whose fracture repair was delayed. ${ }^{89}$ Again, some consideration should be given to earlier repair (immediate or within a few days) in cases where periorbital tissues may be entrapped and damaged.

The reported incidence of enophthalmos following surgical repair ranges from $7 \%$ to $27 \% .{ }^{86,88-90}$ Fat atrophy is speculated as a common reason for this finding, but it may be due to inadequate reconstruction of the orbital cone. . $^{38,87,91}$ Fortunately, this can be corrected with secondary implant augmentation (additional plates or replacement) approximately 3 months after the initial surgery.

Avoiding the use of subciliary incisions may decrease the incidence of postsurgical ectropion. However, more subtle eyelid changes have not been well studied. Raschke et al reviewed over 300 patients who underwent either a transconjunctival or subciliary approach, and noted that subciliary incisions resulted in an increased incidence of scleral show. ${ }^{92}$ This finding can result in dry eye issues as well as an aesthetic change.

\section{Future developments}

It should be our goal to reduce the occurrence of the aforementioned complications - many of which are related to 
inadequate intraoperative assessment and implant placement. Less traumatic surgery with more accurate anatomic reconstruction is needed. Further studies are needed to determine which cases are best approached endoscopically. Large, more complex fractures will likely continue to require a transconjunctival approach in order to place PSIs. Currently, several centers are using preoperative CT imaging to quickly create customized 3D implants for each individual defect. ${ }^{72,93,94}$ Intraoperative navigation can then be used to precisely place the implant according to the preoperative planning based upon the normal orbit. ${ }^{93}$ Rapid, cost-effective production of such implants is the next logical step, and developments in point-of-care 3D printing are promising. Customized orbital implants and intraoperative CT imaging used with image guidance technology should improve accuracy of implant placement and lead to better patient outcomes.

\section{Disclosure}

The authors report no conflicts of interest in this work.

\section{References}

1. Cruz AA, Eichenberger GC. Epidemiology and management of orbital fractures. Curr Opin Ophthalmol. 2004;15(5):416-421.

2. Hwang K, You SH, Sohn IA. Analysis of orbital bone fractures: a 12-year study of 391 patients. J Craniofacial Surg. 2009;20(4):1218-1223.

3. Shere JL, Boole JR, Holtel MR, Amoroso PJ. An analysis of 3599 midfacial and 1141 orbital blowout fractures among 4426 United States Army Soldiers, 1980-2000. Otolaryngol Head Neck Surg. 2004;130(2):164-170.

4. Erdmann D, Follmar KE, Debruijn M, et al. A retrospective analysis of facial fracture etiologies. Ann Plast Surg. 2008;60(4):398-403.

5. Oppenheimer AJ, Monson LA, Buchman SR. Pediatric orbital fractures. Craniomaxillofac Trauma Reconstr. 2013;6(1):9-20.

6. Carinci F, Zollino I, Brunelli G, Cenzi R. Orbital fractures: a new classification and staging of 190 patients. J Craniofac Surg. 2006;17(6) 1040-1044.

7. Manolidis S, Weeks BH, Kirby M, Scarlett M, Hollier L. Classification and surgical management of orbital fractures: experience with 111 orbital reconstructions. J Craniofac Surg. 2002;13(6):726-737; discussion 738 .

8. Kunz C, Audige L, Cornelius CP, Buitrago-Tellez CH, Rudderman R, Prein J. The comprehensive AOCMF classification system: orbital fractures - level 3 tutorial. Craniomaxillofac Trauma Reconstr. 2014; 7(Suppl 1):S092-S102.

9. Harris GJ, Garcia GH, Logani SC, Murphy ML. Correlation of preoperative computed tomography and postoperative ocular motility in orbital blowout fractures. Ophthal Plast Reconstr Surg. 2000;16(3):179-187.

10. Pfeiffer RL. Traumatic enophthalmos. Trans Am Ophthalmol Soc. 1943;41:293-306.

11. Smith B, Regan WF Jr. Blow-out fracture of the orbit; mechanism and correction of internal orbital fracture. Am J Ophthalmol. 1957;44(6):733-739.

12. King EF, Samuel E. Fractures of the orbit. Trans Ophthalmol Soc U K. 1944;64:134-153.

13. Kreidl KO, Kim DY, Mansour SE. Prevalence of significant intraocular sequelae in blunt orbital trauma. Am J Emerg Med. 2003;21(7):525-528.

14. Ansari MH. Blindness after facial fractures: a 19-year retrospective study. J Oral Maxillofac Surg. 2005;63(2):229-237.
15. Ugboko V, Udoye C, Ndukwe K, Amole A, Aregbesola S. Zygomatic complex fractures in a suburban Nigerian population. Dent Traumatol. 2005;21(2):70-75.

16. Dancey A, Perry M, Silva DC. Blindness after blunt facial trauma: are there any clinical clues to early recognition? J Trauma. 2005; 58(2):328-335.

17. Magarakis M, Mundinger GS, Kelamis JA, Dorafshar AH, Bojovic B, Rodriguez ED. Ocular injury, visual impairment, and blindness associated with facial fractures: a systematic literature review. Plast Reconstruct Surg. 2012;129(1):227-233.

18. He D, Blomquist PH, Ellis E 3rd. Association between ocular injuries and internal orbital fractures. J Oral Maxillofac Surg. 2007;65(4):713-720.

19. Holmgren EP, Dierks EJ, Homer LD, Potter BE. Facial computed tomography use in trauma patients who require a head computed tomogram. J Oral Maxillofac Surg. 2004;62(8):913-918.

20. Andreasen JO, Jensen SS, Schwartz O, Hillerup Y. A systematic review of prophylactic antibiotics in the surgical treatment of maxillofacial fractures. J Oral Maxillofac Surg. 2006;64(11):1664-1668.

21. Knepil GJ, Loukota RA. Outcomes of prophylactic antibiotics following surgery for zygomatic bone fractures. J Craniomaxillofac Surg. 2010;38(2):131-133.

22. Zix J, Schaller B, Iizuka T, Lieger O. The role of postoperative prophylactic antibiotics in the treatment of facial fractures: a randomised, double-blind, placebo-controlled pilot clinical study. Part 1: orbital fractures in 62 patients. Br J Oral Maxillofac Surg. 2013;51(4):332-336.

23. Mundinger GS, Borsuk DE, Okhah Z, et al. Antibiotics and facial fractures: evidence-based recommendations compared with experience-based practice. Craniomaxillofac Trauma Reconstr. 2015;8(1):64-78.

24. Chole RA, Yee J. Antibiotic prophylaxis for facial fractures. A prospective, randomized clinical trial. Arch Otolaryngol Head Neck Surg. 1987;113(10):1055-1057.

25. Larsen OD, Nielsen A. Mandibular fractures II. A follow-up study of 229 patients. Scand J Plast Reconstr Surg. 1976;10(3):219-226.

26. Ben Simon GJ, Bush S, Selva D, McNab AA. Orbital cellulitis: a rare complication after orbital blowout fracture. Ophthalmology. 2005;112(11):2030-2034.

27. Putterman AM, Stevens T, Urist MJ. Nonsurgical management of blow-out fractures of the orbital floor. Am J Ophthalmol. 1974;77(2): 232-239.

28. Lynham AJ, Chapman PJ, Monsour FN, et al. Management of isolated orbital floor blow-out fractures: a survey of Australian and New Zealand oral and maxillofacial surgeons. Clin Exp Ophthalmol. 2004;32(1):42-45.

29. Kim BB, Qaqish C, Frangos J, Caccamese JF Jr. Oculocardiac reflex induced by an orbital floor fracture: report of a case and review of the literature. J Oral Maxillofac Surg. 2012;70(11):2614-2619.

30. Gerbino G, Roccia F, Bianchi FA, Zavattero E. Surgical management of orbital trapdoor fracture in a pediatric population. J Oral Maxillofac Surg. 2010;68(6):1310-1316.

31. Jordan DR, Allen LH, White J, Harvey J, Pashby R, Esmaeli B. Intervention within days for some orbital floor fractures: the white-eyed blowout. Ophthal Plast Reconstr Surg. 1998;14(6):379-390.

32. Grant JH 3rd, Patrinely JR, Weiss AH, Kierney PC, Gruss JS. Trapdoor fracture of the orbit in a pediatric population. Plast Reconstructive Surgery. 2002;109(2):482-489; discussion 490-485.

33. Burnstine MA. Clinical recommendations for repair of isolated orbital floor fractures: an evidence-based analysis. Ophthalmology. 2002;109(7):1207-1210; discussion 1210-1201; quiz 1212-1203.

34. Burnstine MA. Clinical recommendations for repair of orbital facial fractures. Curr Opin Ophthalmol. 2003;14(5):236-240.

35. Liao JC, Elmalem VI, Wells TS, Harris GJ. Surgical timing and postoperative ocular motility in type B orbital blowout fractures. Ophthal Plast Reconstr Surg. 2015;31(1):29-33.

36. Egbert JE, May K, Kersten RC, Kulwin DR. Pediatric orbital floor fracture: direct extraocular muscle involvement. Ophthalmology. 2000;107(10):1875-1879. 
37. Bansagi ZC, Meyer DR. Internal orbital fractures in the pediatric age group: characterization and management. Ophthalmology. 2000;107(5):829-836.

38. Gart MS, Gosain AK. Evidence-based medicine: orbital floor fractures. Plast Reconstr Surg. 2014;134(6):1345-1355.

39. Ellis E 3rd. Orbital trauma. Oral Maxillofac Surg Clin North Am. 2012;24(4):629-648.

40. Boush GA, Lemke BN. Progressive infraorbital nerve hypesthesia as a primary indication for blow-out fracture repair. Ophthal Plast Reconstr Surg. 1994;10(4):271-275.

41. Koo L, Hatton MP, Rubin PA. When is enophthalmos "significant"? Ophthal Plast Reconstr Surg. 2006;22(4):274-277.

42. Whitehouse RW, Batterbury M, Jackson A, Noble JL. Prediction of enophthalmos by computed tomography after 'blow out' orbital fracture. Br J Ophthalmol. 1994;78(8):618-620.

43. Ploder O, Klug C, Voracek M, Burggasser G, Czerny C. Evaluation of computer-based area and volume measurement from coronal computed tomography scans in isolated blowout fractures of the orbital floor. J Oral Maxillofac Surg. 2002;60(11):1267-1272; discussion 1273-1264.

44. Hawes MJ, Dortzbach RK. Surgery on orbital floor fractures. Influence of time of repair and fracture size. Ophthalmology. 1983;90(9):1066-1070.

45. Burm JS, Oh SJ. Direct local approach through a W-shaped incision in moderate or severe blowout fractures of the medial orbital wall. Plast Reconstr Surg. 2001;107(4):920-928.

46. Biesman BS, Hornblass A, Lisman R, Kazlas M. Diplopia after surgical repair of orbital floor fractures. Ophthal Plast Reconstr Surg. 1996;12(1):9-16; discussion 17.

47. Matic DB, Tse R, Banerjee A, Moore CC. Rounding of the inferior rectus muscle as a predictor of enophthalmos in orbital floor fractures. J Craniofac Surg. 2007;18(1):127-132.

48. Yano H, Nakano M, Anraku K, et al. A consecutive case review of orbital blowout fractures and recommendations for comprehensive management. Plast Reconstr Surg. 2009;124(2):602-611.

49. Simon GJ, Syed HM, McCann JD, Goldberg RA. Early versus late repair of orbital blowout fractures. Ophthalmic Surg Lasers Imaging. 2009;40(2):141-148.

50. Kothari NA, Avashia YJ, Lemelman BT, Mir HS, Thaller SR. Incisions for orbital floor exploration. J Craniofac Surg. 2012;23(7 Suppl 1): 1985-1989.

51. Holtmann B, Wray RC, Little AG. A randomized comparison of four incisions for orbital fractures. Plast Reconstr Surg. 1981;67(6):731-737.

52. Ridgway EB, Chen C, Colakoglu S, Gautam S, Lee BT. The incidence of lower eyelid malposition after facial fracture repair: a retrospective study and meta-analysis comparing subtarsal, subciliary, and transconjunctival incisions. Plast Reconstr Surg. 2009;124(5):1578-1586.

53. Feldman EM, Bruner TW, Sharabi SE, Koshy JC, Hollier LH Jr. The subtarsal incision: where should it be placed? J Oral Maxillofac Surg. 2011;69(9):2419-2423.

54. Mullins JB, Holds JB, Branham GH, Thomas JR. Complications of the transconjunctival approach. A review of 400 cases. Arch Otolaryngol Head Neck Surg. 1997;123(4):385-388.

55. Zingg M, Chowdhury K, Ladrach K, Vuillemin T, Sutter F, Raveh J. Treatment of 813 zygoma-lateral orbital complex fractures. New aspects. Arch Otolaryngol Head Neck Surg. 1991;117(6):611-620; discussion 621-612.

56. Westfall CT, Shore JW, Nunery WR, Hawes MJ, Yaremchuk MJ. Operative complications of the transconjunctival inferior fornix approach. Ophthalmology. 1991;98(10):1525-1528.

57. Cheung K, Voineskos SH, Avram R, Sommer DD. A systematic review of the endoscopic management of orbital floor fractures. JAMA Facial Plast Surg. 2013;15(2):126-130.

58. Ducic Y, Verret DJ. Endoscopic transantral repair of orbital floor fractures. Otolaryngol Head Neck Surg. 2009;140(6):849-854.

59. Bly RA, Chang SH, Cudejkova M, Liu JJ, Moe KS. Computer-guided orbital reconstruction to improve outcomes. JAMA Facial Plast Surg. 2013;15(2):113-120.
60. Shaye DA, Tollefson TT, Strong EB. Use of intraoperative computed tomography for maxillofacial reconstructive surgery. JAMA Facial Plast Surg. 2015;17(2):113-119.

61. Strong EB. Orbital fractures: pathophysiology and implant materials for orbital reconstruction. Facial Plast Surg. 2014;30(5):509-517.

62. Gunarajah DR, Samman N. Biomaterials for repair of orbital floor blowout fractures: a systematic review. J Oral Maxillofac Surg. 2013;71(3):550-570.

63. Zunz E, Blanc O, Leibovitch I. Traumatic orbital floor fractures: repair with autogenous bone grafts in a tertiary trauma center. $J$ Oral Maxillofac Surg. 2012;70(3):584-592.

64. Ellis E 3rd, Tan Y. Assessment of internal orbital reconstructions for pure blowout fractures: cranial bone grafts versus titanium mesh. J Oral Maxillofac Surg. 2003;61(4):442-453.

65. Guo L, Tian W, Feng F, Long J, Li P, Tang W. Reconstruction of orbital floor fractures: comparison of individual prefabricated titanium implants and calvarial bone grafts. Ann Plast Surg. 2009; 63(6):624-631.

66. Kontio RK, Laine P, Salo A, Paukku P, Lindqvist C, Suuronen R. Reconstruction of internal orbital wall fracture with iliac crest free bone graft: clinical, computed tomography, and magnetic resonance imaging follow-up study. Plast Reconstr Surg. 2006;118(6):1365-1374.

67. Bayat M, Momen-Heravi F, Khalilzadeh O, Mirhosseni Z, Sadeghi-Tari A. Comparison of conchal cartilage graft with nasal septal cartilage graft for reconstruction of orbital floor blowout fractures. Br J Oral Maxillofac Surg. 2010;48(8):617-620.

68. Talesh KT, Babaee S, Vahdati SA, Tabeshfar S. Effectiveness of a nasoseptal cartilaginous graft for repairing traumatic fractures of the inferior orbital wall. Br J Oral Maxillofac Surg. 2009;47(1):10-13.

69. Sugar AW, Kuriakose M, Walshaw ND. Titanium mesh in orbital wall reconstruction. Int J Oral Maxillofac Surg. 1992;21(3):140-144.

70. Yilmaz M, Vayvada H, Aydin E, Menderes A, Atabey A. Repair of fractures of the orbital floor with porous polyethylene implants. $\mathrm{Br} J$ Oral Maxillofac Surg. 2007;45(8):640-644.

71. Dietz A, Ziegler CM, Dacho A, et al. Effectiveness of a new perforated $0.15 \mathrm{~mm}$ poly-p-dioxanon-foil versus titanium-dynamic mesh in reconstruction of the orbital floor. J Craniomaxillofac Surg. 2001;29(2):82-88.

72. Gander T, Essig H, Metzler P, et al. Patient specific implants (PSI) in reconstruction of orbital floor and wall fractures. $J$ Craniomaxillofac Surg. 2015;43(1):126-130.

73. Alonso-Rodriguez E, Cebrian JL, Nieto MJ, Del Castillo JL, HernandezGodoy J, Burgueno M. Polyetheretherketone custom-made implants for craniofacial defects: report of 14 cases and review of the literature. J Craniomaxillofac Surg. 2015;43(7):1232-1238.

74. Marbacher S, Andereggen L, Fandino J, Lukes A. Combined bone and soft-tissue augmentation surgery in temporo-orbital contour reconstruction. J Craniofac Surg. 2011;22(1):266-268.

75. Klein M, Glatzer C. Individual CAD/CAM fabricated glass-bioceramic implants in reconstructive surgery of the bony orbital floor. Plast Reconstr Surg. 2006;117(2):565-570.

76. Mertens C, Lowenheim H, Hoffmann J. Image data based reconstruction of the midface using a patient-specific implant in combination with a vascularized osteomyocutaneous scapular flap. $J$ Craniomaxillofac Surg. 2013;41(3):219-225.

77. Stoor P, Suomalainen A, Lindqvist C, et al. Rapid prototyped patient specific implants for reconstruction of orbital wall defects. J Craniomaxillofac Surg. 2014;42(8):1644-1649.

78. Morris C, Kushner GM, Tiwana PS. Facial skeletal trauma in the growing patient. Oral Maxillofac Surg Clin North Am. 2012;24(3):351-364.

79. Grunwaldt L, Smith DM, Zuckerbraun NS, et al. Pediatric facial fractures: demographics, injury patterns, and associated injuries in 772 consecutive patients. Plast Reconstr Surg. 2011;128(6): $1263-1271$.

80. Haug RH, Van Sickels JE, Jenkins WS. Demographics and treatment options for orbital roof fractures. Oral Surg Oral Med Oral Pathol Oral Radiol Endod. 2002;93(3):238-246. 
81. Rottgers SA, Decesare G, Chao M, et al. Outcomes in pediatric facial fractures: early follow-up in 177 children and classification scheme. J Craniofac Surg. 2011;22(4):1260-1265.

82. Losee JE, Afifi A, Jiang S, et al. Pediatric orbital fractures: classification, management, and early follow-up. Plast Reconstr Surg. 2008;122(3):886-897.

83. Joshi S, Kassira W, Thaller SR. Overview of pediatric orbital fractures. J Craniofac Surg. 2011;22(4):1330-1332.

84. Hollier LH, Rogers N, Berzin E, Stal S. Resorbable mesh in the treatment of orbital floor fractures. J Craniofac Surg. 2001;12(3):242-246.

85. Girotto JA, Gamble WB, Robertson B, et al. Blindness after reduction of facial fractures. Plast Reconstr Surg. 1998;102(6):1821-1834.

86. Chi MJ, Ku M, Shin KH, Baek S. An analysis of 733 surgically treated blowout fractures. Ophthalmologica. 2010;224(3):167-175.

87. Chen CT, Huang F, Chen YR. Management of posttraumatic enophthalmos. Chang Gung Med J. 2006;29(3):251-261.

88. Greenwald HS Jr, Keeney AH, Shannon GM. A review of 128 patients with orbital fractures. Am J Ophthalmol. 1974;78(4):655-664.
89. Hosal BM, Beatty RL. Diplopia and enophthalmos after surgical repair of blowout fracture. Orbit. 2002;21(1):27-33.

90. Brucoli M, Arcuri F, Cavenaghi R, Benech A. Analysis of complications after surgical repair of orbital fractures. J Craniofac Surg. 2011;22(4):1387-1390.

91. Cole P, Kaufman Y, Hollier L. Principles of facial trauma: orbital fracture management. J Craniofac Surg. 2009;20(1):101-104.

92. Raschke G, Rieger U, Bader RD, Schaefer O, Guentsch A, Schultze-Mosgau $\mathrm{S}$. Outcomes analysis of eyelid deformities using photograph-assisted standardized anthropometry in 311 patients after orbital fracture treatment. J Trauma Acute Care Surg. 2012;73(5):1319-1325.

93. Rana M, Chui CH, Wagner M, Zimmerer R, Rana M, Gellrich NC. Increasing the accuracy of orbital reconstruction with selective lasermelted patient-specific implants combined with intraoperative navigation. J Oral Maxillofac Surg. 2015;73(6):1113-1118.

94. Kozakiewicz M. Computer-aided orbital wall defects treatment by individual design ultrahigh molecular weight polyethylene implants. J Craniomaxillofac Surg. 2014;42(4):283-289.
Clinical Ophthalmology

\section{Publish your work in this journal}

Clinical Ophthalmology is an international, peer-reviewed journal covering all subspecialties within ophthalmology. Key topics include: Optometry; Visual science; Pharmacology and drug therapy in eye diseases; Basic Sciences; Primary and Secondary eye care; Patien Safety and Quality of Care Improvements. This journal is indexed on

\section{Dovepress}

PubMed Central and CAS, and is the official journal of The Society of Clinical Ophthalmology (SCO). The manuscript management system is completely online and includes a very quick and fair peer-review system, which is all easy to use. Visit http://www.dovepress.com/ testimonials.php to read real quotes from published authors. 